\title{
Do we need new trials of procalcitonin- guided antibiotic therapy?
}

Thiago Lisboa ${ }^{1,2^{*}}$, Jorge Salluh $h^{3,4}$ and Pedro Povoa ${ }^{5,6}$

\begin{abstract}
Using biomarkers as a guide to tailor the duration of antibiotic treatment in respiratory infections is an attractive hypothesis assessed in several studies. Recent work aiming to summarize the evidence assessed the effect of a procalcitonin (PCT)-guided antibiotic treatment on outcomes in acute lower respiratory tract infections (LRTI), suggesting that significant reductions in antibiotic duration occur when using a PCT-guided algorithm. However, controversial evidence also suggested PCT-guided algorithms were associated with increased antibiotic duration and increased incidence of Clostridium difficile, without any impact on mortality, in real-world settings. So, although using PCT-guided antibiotic stewardship is promising, after more than a decade of randomized controlled trials on this topic the evidence in its favor is still less than compelling due to limitations in trial design, not taking into consideration fundamental aspects of PCT biology, and the absence of evidence-based antimicrobial duration in intervention and control groups. In this commentary we highlight some questions and limitations of primary PCT study data that might impact interpretation and clinical use of PCT at the bedside.
\end{abstract}

\section{Introduction}

Using biomarkers as a guide to tailor the duration of antibiotic treatment in respiratory infections is an attractive hypothesis assessed in several studies. A recent meta-analysis aiming to summarize the evidence assessed the effect of a procalcitonin (PCT)-guided antibiotic treatment on outcomes in acute lower respiratory tract infections (LRTI) suggested significant reductions in antibiotic duration occur when using a PCT-guided algorithm [1]. However, its use in "real-world" conditions was recently challenged by $\mathrm{Chu}$ et al. [2], who found that the use of PCT-guided algorithms was associated with increased antibiotic duration and increased incidence of Clostridium difficile, without any impact on mortality, in real-world settings in the US. In this commentary, we highlight some questions and limitations of primary PCT study data that might impact interpretation and clinical use of PCT at the bedside.

\footnotetext{
*Correspondence: tlisboa@hotmail.com

${ }^{1}$ Rede Institucional de Pesquisa e Inovação em Medicina Intensiva, Complexo Hospitalar Santa Casa de Misericordia de Porto Alegre, Porto Alegre, Brazil ${ }^{2}$ Critical Care Department and Infection Control Committee, Hospital de Clinicas de Porto Alegre, Porto Alegre, Brazil

Full list of author information is available at the end of the article
}

\section{Are control groups receiving the best care?}

A major concern in PCT-guided trials is antibiotic use in the control group. According to the World Medical Association's Helsinki declaration, "the benefits, risks, burdens, and effectiveness of a new intervention must be tested against those of the best current proven intervention," but defining "best current proven intervention" is difficult [3]. Heterogeneity of current practices has been a major argument against using routine care without any constraints as the comparator. When we consider duration of antibiotic treatment and/or antibiotic exposure, the duration of therapy in control groups is systematically above those recommended by guidelines and the best available evidence base (e.g., standard of care for ventilator-associated pneumonia (VAP) patients in the control group should be 6-8 days, not 13 days $[4,5])$. Should any intervention compared to a "suboptimal" standard of care (even when it is usual care) be recommended/adopted in clinical practice?

For instance, usual care is sometimes far from the best available care or what should be standard of care. Trials using a protocolized rather than an unrestricted standard care control group will likely have enhanced validity as long as the protocolized care control group is representative of standard care practices [6]. In PCT studies, a protocolized group with clear stop rules for antibiotic 
duration, making it more compatible with best available evidence and recommendations, would be important and could lead to better evaluation of biomarker-based antimicrobial treatment [7].

\section{Are PCT algorithms really followed?}

Also, PCT algorithms consider that a PCT $<0.1 \mu \mathrm{g} / \mathrm{L}$ bacterial infection is very unlikely and antibiotics should not be prescribed or should be withheld. It is well known that in several bacterial infections, for example, VAP $[8,9]$, PCT is not a good marker of diagnosis since it presents a high rate of false negatives. However, it was with some surprise that we realized that the rate of PCT false negatives among the patients diagnosed with LRTI included in the 32 randomized controlled trials (RCT) of the above-mentioned meta-analysis was well above 30\% [1]! The authors did not give this information according to the setting nor according to the infection. In the ICU setting, doctors almost always wisely overrule this recommendation, as was very clear in the PRORATA trial (overruling the algorithm at inclusion $21 \%$ of the time) [10], since the "blind" application of the algorithm could be unsafe. Also, very low PCT levels on enrolment $(>40 \% \mathrm{PCT}<0.25 \mu \mathrm{g} / \mathrm{L})$ raises another problem. Every PCT algorithm is based on the assessment of absolute and/or relative variations of PCT measurements during the course of antibiotic therapy in relation to the baseline value. This so-called lack of amplitude of variation of PCT is another limitation of its clinical applicability not discussed in the study.

\section{Are PCT limitations addressed?}

In addition, another important limitation of PCT use is related to the lack of information on specific conditions and populations where its value is inadequate because of intrinsic constraints. In critically ill patients the presence of acute kidney injury or the use of renal replacement therapies has a profound effect on PCT concentrations [11-14]. Additionally, PCT tends to be less responsive to repeated inflammatory insults (such as VAP or nosocomial bloodstream infections), resulting in lower than expected peak concentrations [15]. Similar findings are described in neutropenic patients, limiting the interpretation and use of PCT in this context [16].

\section{Conclusions}

Clinical use of biomarker-guided antibiotic stewardship such as PCT is promising, but after more than a decade of RCTs on the topic the evidence in its favor is still less than compelling due to limitations in trial design. These limitations include not taking into consideration fundamental aspects of PCT biology and the absence of evidence-based antimicrobial duration in intervention and control groups, namely in VAP. A double-trigger criteria, in which antibiotics are stopped according to the clinical course and either decreases in biomarker levels, according to an algorithm, or the completion of 5-7 days of treatment, whichever comes first [17], might be a safe and efficient strategy to decrease antimicrobial therapy duration in critically ill patients.

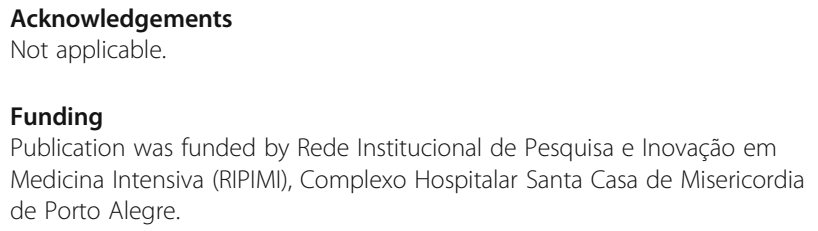

Availability of data and material

Data sharing not applicable to this article as no datasets were generated or analyzed during the current study.

Authors' contributions

$T L$, JS, and PP drafted, discussed, and approved the final version of this manuscript.

Ethics approval and consent to participate

Not applicable.

Consent for publication

Not applicable.

Competing interests

The authors declare that they have no competing interests.

\section{Publisher's Note}

Springer Nature remains neutral with regard to jurisdictional claims in published maps and institutional affiliations.

\section{Author details}

${ }^{1}$ Rede Institucional de Pesquisa e Inovação em Medicina Intensiva, Complexo Hospitalar Santa Casa de Misericordia de Porto Alegre, Porto Alegre, Brazil.

${ }^{2}$ Critical Care Department and Infection Control Committee, Hospital de Clinicas de Porto Alegre, Porto Alegre, Brazil. ${ }^{3}$ Instituto D'OR de pesquisa e ensino, Rio de Janeiro, Brazil. ${ }^{4}$ Programa de pós-graduação de Clinica Medica Universidade Federal do Rio de Janeiro_-UFRJ, Rio de Janeiro, Brazil.

${ }^{5}$ Unidade de Cuidados Intensivos Polivalente, Hospital de São Francisco Xavier, Centro Hospitalar de Lisboa Ocidental, Lisboa, Portugal. ${ }^{6}$ NOVA Medical School, CEDOC, Universidade Nova de Lisboa, Lisboa, Portugal.

Received: 22 December 2017 Accepted: 9 January 2018

Published online: 27 January 2018

\section{References}

1. Schuetz P, Wirz Y, Sager R, et al. Effect of procalcitonin-guided antibiotic treatment on mortality in acute respiratory infections: a patient level metaanalysis. Lancet Infect Dis. 2018;18(1):95-107.

2. Chu DC, Mehta AB, Walkey AJ. Practice patterns and outcomes associated with procalcitonin use in critically ill patients with sepsis. Clin Infect Dis. 2017;64(11):1509-15

3. Takala J. Better conduct of clinical trials: the control group in critical care trials. Crit Care Med. 2009;37(1 Suppl):S80-90.

4. Chastre J, Wolff M, Fagon JY, et al. Comparison of 8 vs 15 days of antibiotic therapy for ventilator-associated pneumonia in adults: a randomized trial. JAMA. 2003;290(19):2588-98.

5. Micek ST, Ward S, Fraser VJ, Kollef MH. A randomized controlled trial of an antibiotic discontinuation policy for clinically suspected ventilator-associated pneumonia. CHEST. 2004;125(5):1791-9.

6. Silverman HJ, Miller FG. Control group selection in critical care randomized controlled trials evaluating interventional strategies: an ethical assessment. Crit Care Med. 2004;32(3):852-7. 
7. Oliveira CF, Botoni FA, Oliveira CR, et al. Procalcitonin versus C-reactive protein for guiding antibiotic therapy in sepsis: a randomized trial. Crit Care Med. 2013;41(10):2336-43.

8. Luyt CE, Combes A, Reynaud C, et al. Usefulness of procalcitonin for the diagnosis of ventilator-associated pneumonia. Intensive Care Med. 2008; 34(8):1434-40.

9. Póvoa P, Martin-Loeches I, Ramirez P, et al. Biomarker kinetics in the prediction of VAP diagnosis: results from the BioVAP study. Ann Intensive Care. 2016;6(1):32

10. Bouadma L, Luyt $C$, Tubach F, et al. Use of procalcitonin to reduce patients' exposure to antibiotics in intensive care units (PRORATA trial): a multicentre randomised controlled trial. Lancet. 2010;375(9713):463-74.

11. Amour J, Birenbaum $\mathrm{A}$, Langeron $\mathrm{O}$, et al. Influence of renal dysfunction on the accuracy of procalcitonin for the diagnosis of postoperative infection after vascular surgery. Crit Care Med. 2008:36:1147-54.

12. Mongardon $\mathrm{N}$, Lemiale $\mathrm{V}$, Perbet $\mathrm{S}$, et al. Value of procalcitonin for diagnosis of early onset pneumonia in hypothermia-treated cardiac arrest patients. Intensive Care Med. 2010;36:92-9.

13. Dahaba AA, Elawady GA, Rehak PH, List WF. Procalcitonin and proinflammatory cytokine clearance during continuous venovenous haemofiltration in septic patients. Anaesth Intensive Care. 2002;30:269-74.

14. Dahaba AA, Rehak PH, List WF. Procalcitonin and C-reactive protein plasma concentrations in nonseptic uremic patients undergoing hemodialysis. Intensive Care Med. 2003;29:579-83.

15. Charles PE, Ladoire $S$, Snauwaert A, et al. Impact of previous sepsis on the accuracy of procalcitonin for the early diagnosis of blood stream infection in critically ill patients. BMC Infect Dis. 2008;8:163.

16. Stolz D, Stulz A, Müller B, et al. BAL neutrophils, serum procalcitonin and $\mathrm{C}$-reactive protein to predict bacterial infection in the immunocompromised host. Chest. 2007;132:504-14.

17. Salluh Jl, Nobre V, Povoa P. Using procalcitonin to guide antimicrobial duration in sepsis: asking the same questions will not bring different answers. Crit Care. 2014;18(3):142. 